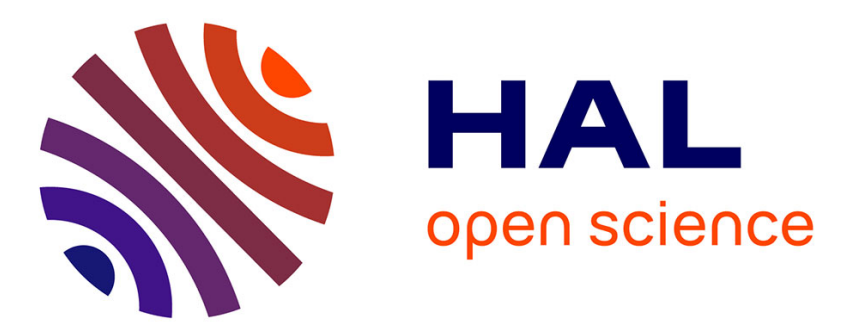

\title{
The observation of a shear flow instability in a rotating system with a soap membrane
}

\author{
Y. Couder
}

\section{To cite this version:}

Y. Couder. The observation of a shear flow instability in a rotating system with a soap membrane. Journal de Physique Lettres, 1981, 42 (19), pp.429-431. 10.1051/jphyslet:019810042019042900 jpa00231966

\section{HAL Id: jpa-00231966 https://hal.science/jpa-00231966}

Submitted on 1 Jan 1981

HAL is a multi-disciplinary open access archive for the deposit and dissemination of scientific research documents, whether they are published or not. The documents may come from teaching and research institutions in France or abroad, or from public or private research centers.
L'archive ouverte pluridisciplinaire HAL, est destinée au dépôt et à la diffusion de documents scientifiques de niveau recherche, publiés ou non, émanant des établissements d'enseignement et de recherche français ou étrangers, des laboratoires publics ou privés. 


\title{
LE JOURNAL DE PHYSIQUE-LETTRES
}

J. Physique - LETTRES 42 (1981) L- 429 - L-431

1er OCTOBRE 1981, PAGE L-42!

\section{The observation of a shear flow instability in a rotating system with a soap membrane}

\author{
Y. Couder \\ Groupe de Physique des Solides de l'Ecole Normale Supérieure (*), 24 rue Lhomond, 75231 Paris Cedex 05, France
}

(Reçu le 1er juin 1981, accepté le 13 août 1981)

Résumé. - Une figure de vortex entretenus peut être observée dans une couche de fluide, soumise au cisaillement dû à un mouvement de rotation. Nous présentons une expérience où une membrane liquide est utilisée pour clore un volume d'air de faible épaisseur. Elle constitue une paroi qui a les propriétés suivantes :

- Elle n'impose pas que la composante de la vitesse parallèle à sa surface soit nulle.

- Elle permet une excellente visualisation des isobares de l'écoulement.

\begin{abstract}
A pattern of driven vortices can be observed in the shear layer created in a fluid by a rotation movement.

We present such an experiment where a liquid membrane is used to close a thin experimental volume of air thus forming a wall with the following properties :

- The parallel component of the fluid velocity does not have to be zero at the boundary.

- The interference fringes provide a good visualization of the isobars of the flow.
\end{abstract}

1. Introduction. - The shear constraint in a fluid surrounding a rotating cylinder can result in the apparition of two types of instabilities. One is axisymmetric but non bidimensional : the apparition of the toroidal structure of Taylor cells in the Couette flow. The other is non-axisymmetric : unstable azimuthal waves grow into a pattern of regular two dimensional vortices similar to those observed in the shear layer between two parallel jets moving at different velocities. The latter type of instability was first observed by Hide and Titman [1] and analysed by Busse [2] and Siegman [3]. Hide experimental set up has a rotating cylinder filled with liquid in the centre of which a disk rotates with a larger angular speed. This system is characterized by low values of the Rossby number $\varepsilon=\left(\Omega_{1}-\Omega_{0}\right) / \frac{1}{2}\left(\Omega_{1}+\Omega_{0}\right)$. A pattern of $n$ vortices shows in the shear layer boundary the disk and its Taylor column. We find comparable patterns in different experimental conditions. We will describe here the experimental set up

(*) Laboratoire associé au Centre National de la Recherche Scientifique. and the type of observations that we can use it for. A quantitative study of our results will be published later.

2. Experimental set up. - The experimental cell (Fig. 1) is a very flat, air filled, cylinder (height $h$, radius $R_{3}$ ). Its upper end has a rim on which a soap membrane can be stretched horizontally, thus closing the volume. The centre of the lower end is the surface of a rotating disk (radius $R_{1}$ ). Its angular velocity $\Omega_{0}$ can be linearly increased from $0.1 \mathrm{rad} . / \mathrm{s}$ to $10 \mathrm{rad} . / \mathrm{s}$. This disk is surrounded by a fixed annulus with an internal radius $R_{2}$ and external radius $R_{3}$. In the

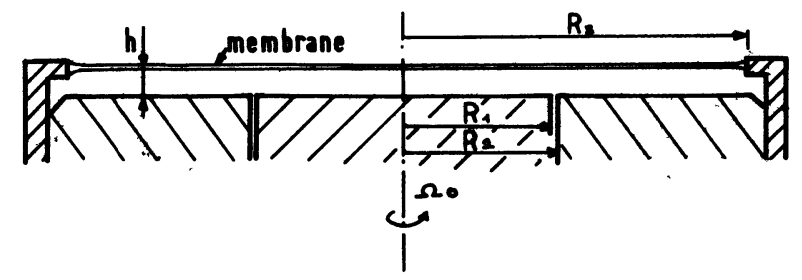

Fig. 1. - The experimental cell. 
experiments we present, we chose the following dimensions :

$$
\begin{array}{lll}
R_{1}=1.9 \mathrm{~cm} & R_{2}=1.95 \text { or } 2.2 \mathrm{~cm} & R_{3}=4.5 \mathrm{~cm} \\
R_{1}=3 \mathrm{~cm} & R_{2}=3.05 \text { or } 3.2 \mathrm{~cm} & R_{3}=4.5 \mathrm{~cm} \\
R_{1}=3.5 \mathrm{~cm} & R_{2}=3.55 \mathrm{~cm} & R_{3}=4.5 \mathrm{~cm}
\end{array}
$$

So that either the rotating disk and its fixed annulus are contiguous or they define an intermediate space.

The minimum height $h$ that we can use in order to avoid accidental contact between the membrane and the bottom of the cylinder is approximately $1 \mathrm{~mm}$.

The soap is chosen so that the membrane is of the mobile type [4], with low viscosity, little visco elastic properties and can still last an average $15 \mathrm{~min}$. for the experiments. Good results were obtained with a solution of $0.7 \%$ of a commercial soap which is a mixture of sodium lauryl sulfate and sodium dodacyl benzene sulfate. The membrane can be made to last longer by adding $10 \%$ of glycerol but the viscosity is then increased.

We use a broad source of sodium light in order to observe the interference fringes. It is necessary to compare the patterns observed on the membrane to the air flow underneath. Therefore, we can deposit droplets of hydrochloric acid and droplets of ammonia in different points of the rotating disk. A white smoke appears with the mixing of the vapours during the rotation. Smoke flows are well observed with a lateral light (the sodium light being removed).

3. Results and discussion. - The central part of the membrane rotates, driven by the disk. For a height $h \sim 1 \mathrm{~mm}$, its angular velocity is approximately $0.75 \Omega_{0}$. In this region, the membrane shows circular fringes corresponding to the thinning of the centre due to slow centrifugation. The part of the membrane overlying the fixed annulus is motionless, the inter-

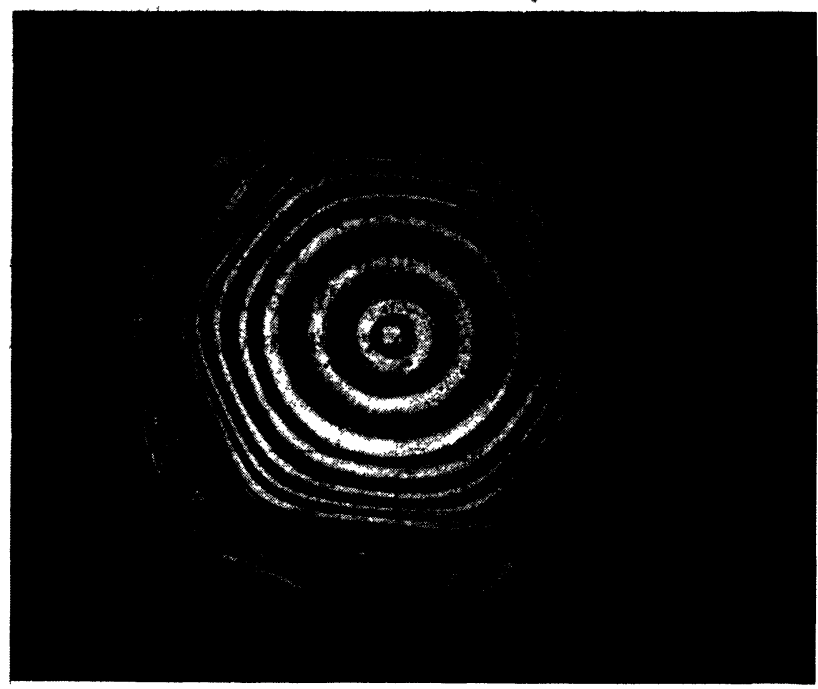

Fig. 2. - Mode $n=6: R_{1}=3.1 \mathrm{~cm}, R_{2}=3.3 \mathrm{~cm}, h=0.13 \mathrm{~cm}$, $\Omega_{0}=3 \mathrm{rad} . \mathrm{s}$.

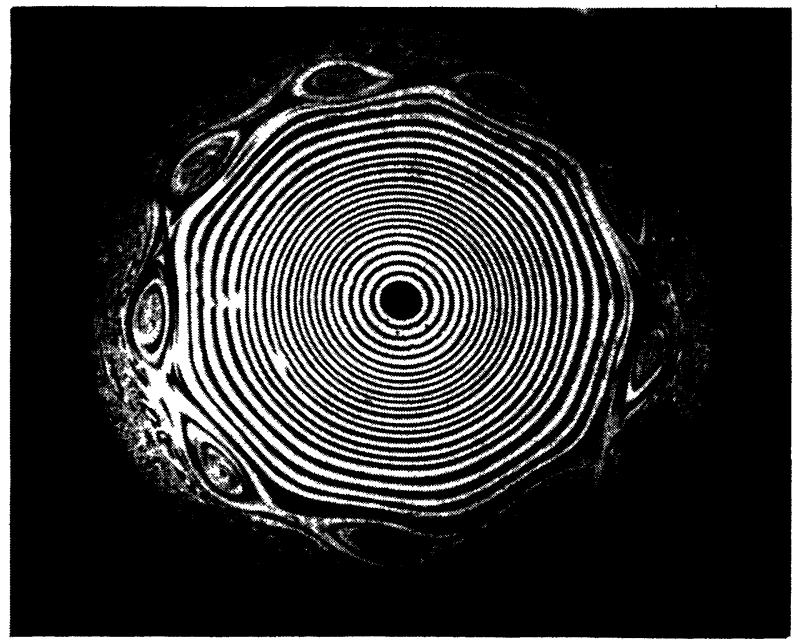

Fig. 3. - Mode $n=9: R_{1}=3.5 \mathrm{~cm}, R_{2}=3.55 \mathrm{~cm}$.

mediate part being submitted to a shear stress similar to that in the air.

Over a critical value $\Omega_{0 \mathrm{c}}$ of the driving velocity, a non-axisymmetric flow shows up in the shear zone with vortices that organize rapidly into a regular mode of $n$ vortices equally spaced, sustained by the rotation (Figs. 2 and 3). $\Omega_{0 \mathrm{c}}$ is $3.3 \mathrm{rad} . / \mathrm{s}$ for $R=3 \mathrm{~cm}$ and $8.2 \mathrm{rad} . / \mathrm{s}$ for $R=1.9 \mathrm{~cm}$ which correspond to values of the Ekmann number in the shear layer

$$
E_{\mathrm{c}}=\frac{2 v}{\Omega_{0 \mathrm{c}} R_{1}^{2}} \sim 10^{-2} .
$$

When $R_{2}>R_{1}$, the first mode to appear, as the driving velocity is increased, is selected by the geometrical factors (perimeter and spacing).

When disk and annulus are contiguous $R_{1} \simeq R_{2}$, a larger number of different modes can show up. With a slow increase of $\Omega_{0}$, modes with high values of $n$ (as large as $n=16$ for $R=3.5 \mathrm{~cm}$ ) can be observed.

Figure 3 shows a mode with $n=9$.

Let us remark that the observation of modes with $n>7$ seems to contradict theoretical predictions by Havelock [5] and that the maximum values of $n$ observed in Hide's experiments were $n=6$. The difference probably lies in the absence of rigid lateral boundary conditions in our experiment.

A mode $n$ is stable within a certain range of values of $\Omega_{0}$ and the whole shape rotates at an angular velocity, which is proportional to $\Omega_{0} \quad \Omega_{1}=\alpha(n) \Omega_{0}$ (where the constant $\alpha$ depends on $n$ ).

\begin{tabular}{l|lllll}
$n$ & 4 & 5 & 6 & 7 & 8 \\
\hline$\alpha$ & 0.25 & 0.285 & 0.345 & 0.37 & 0.43
\end{tabular}

When the shear stress is relatively weak, the shape of each vortex is close to the shape of vortices in a linear shear layer [6]. Being in the $n$th mode a slow increase of $\Omega_{0}$ produces as a consequence an increase 
of the dimensions of the vortex until a point where the $n$th mode is no longer stable. Global oscillations of the vortices amplitude are observed (Fig. 4) then the pairing of vortices rolling around each other leads to the coalescence of one or several pairs. The pattern then becomes a regular n-p shape.

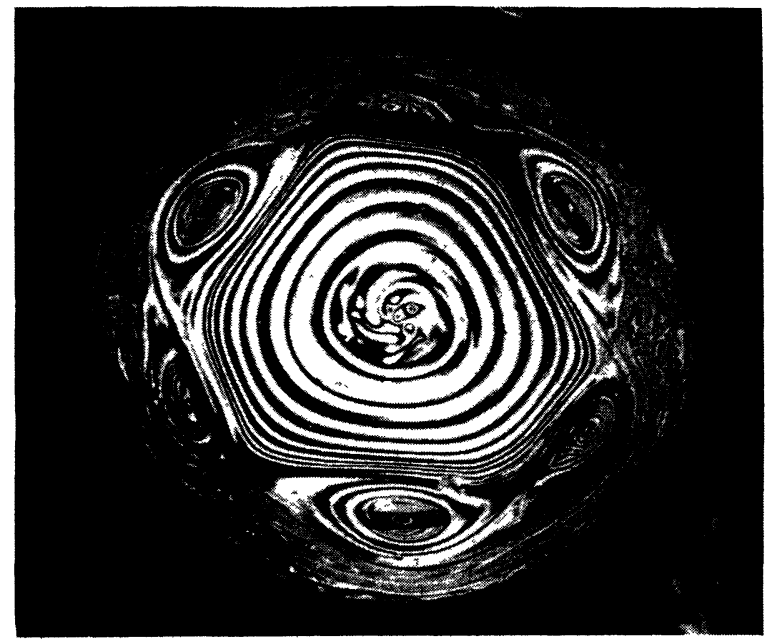

Fig. 4. Oscillations of the $n=6$ mode, $\Omega_{0}=5 \mathrm{rad} . / \mathrm{s}$.

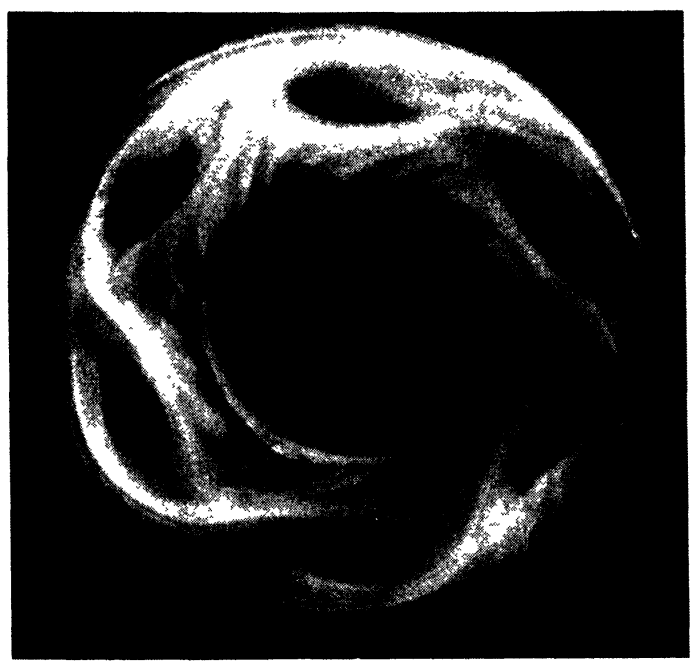

Fig. 5. - Mode $n=6: \Omega_{0}=3.2 \mathrm{rad} . / \mathrm{s}$.

The bidimensional movement observed on the membrane is driven by the underlying air. Figure 5 shows the smoke flow seen in a thin layer of air with $h \sim 2 \mathrm{~mm}$. For this order of thickness, the movement can only be observed with a membrane as a boundary.
If it is replaced by a glass plate the structure can no longer be seen in the smoke, the friction being too strong. Only with a much larger value of $h(h \sim 5 \mathrm{~mm})$ can similar structures be observed with either a glass or a membrane boundary. But the whole shape is then different with a central vortex surrounded by $n$ satellite vortices. On the membrane the shape of the vortices, when $h$ and $\Omega_{0}$ are large, is different with a strong asymmetry between strong centrifugal jets and large zones of centripetal flow.

4. Role of the membrane. - The membrane, with a thickness of a few microns, has a mass of a few $\mathrm{mg} / \mathrm{cm}^{2}$. Being light and having a low viscosity, it is easily dragged by any flow of air parallel to its surface. In turn, the membrane drags the overlying air. (In a few experiments we superpose a second membrane $1 \mathrm{~mm}$ over the first one; the same vortex pattern showed on both membranes.) The liquid membrane and the underlying air form something like a stratified fluid where vertical movements are suppressed so that similar two-dimensional movements are observed in both the air and the membrane.

As the curvature due to its weight is negligible, the membrane can be considered as initially plane. The capillar forces oppose any deformation of this plane. However very slight dips, due to the depression created by the eddy, mark the centre of each vortex.

The interference fringes seen on the membrane are lines of equal thickness. The thinning factor is centrifugation due to the rotations around the centre and around each of the vortices cores. Thus, in this experiment, the fringes pattern correspond to the isobars of the system.

The particle paths can also be observed using the micelles suspended in the membrane.

In conclusion, the use of a liquid membrane to close a gas filled volume provides a particular type of boundary which could be used for other types of hydrodynamics experiments. Here it enables us to work in a geometry where quantified vortex patterns are created. Unlike in previous experiments, rings with a large number of vortices are observed. The quality of the visualization will allow a precise study of the selection of modes in each geometry as well as of the oscillations that precede transitions from one mode to another.

I am grateful to C. Guthmann, A. Libchaber and B. Perrin for many helpful discussions and to J. Brochard and $\mathrm{H}$. Thomé for technical support.

\section{References}

[1] Hide, R. and Trtman, C. W., J. Fluid Mech. 29 part 1 (1967) 39.

[2] BusSE, F. H., J. Fluid Mech. 64 part 3 (1968) 577.

[3] SifgmanN, W. L., J. Fluid Mech. 64 part 2 (1974) 289.

[4] Mysels, K. J., Shinoda, K., Frankel, S., Soap films Studies of their thinning and a bibliography (Pergamon Press) 1959.
[5] Havelock, T. H., Philos. Mag. 57, 11 (1931) 617.

[6] Pierrehumbert, R. T. and Widnall, S. E., J. Fluid Mech. 102 (1981) 301. 